Article

\title{
Market Efficiency and Behavioral Biases in the WNBA Betting Market
}

\section{Rodney J. Paul ${ }^{1} *$ and Andrew P. Weinbach ${ }^{2}$}

1 Department of Sport Management, David B. Falk College of Sport and Human Dynamics, Syracuse University, 810 Nottingham Road, Syracuse, NY 13224-8165, USA

2 E. Craig Wall Sr. College of Business Administration, Coastal Carolina University, P.O. Box 261954, Conway, SC 26195, USA; E-Mail: aweinbac@ coastal.edu

* Author to whom correspondence should be addressed; E-Mail: rpaul01 @ syr.edu; Tel.: +1-585-748-5092; Fax: +1-315-443-9716.

Received: 24 February 2014; in revised form: 9 April 2014 / Accepted: 14 April 2014 / Published: 24 April 2014

\begin{abstract}
The betting market for the Women's National Basketball Association (WNBA) is a thin financial market, which does not attract much interest from sports bettors. Given these characteristics, it is possible that profitable wagering strategies could exist for informed bettors of the WNBA. Using betting data on the WNBA from 2007-2012, we find that simple betting strategies do not earn statistically significant returns. WNBA bettors are like NBA bettors; however, in that they strongly prefer the best teams, particularly when they are on the road. Despite this clear bias, betting against the most popular public wagers is not found to earn statistically significant profits.
\end{abstract}

Keywords: efficient markets; gambling; behavioral biases

JEL Classification: G14, G10, G02

\section{Introduction}

Most of the betting on professional basketball in the United States is tied to National Basketball Association (NBA) games, the dominant men's league which offers the greatest exposure and highest salaries in the world of basketball. Women's basketball also has a professional league in North America, the WNBA. A wagering market also exists for the WNBA, but the betting market for the WNBA 
is quite small and attracts little interest relative to the NBA. According to records of data from [1], for participating sportsbooks, the average betting volume for a WNBA game is under 1200 bets per game, which is extremely small compared to the average betting volume in men's professional and college sports. In comparison, NBA games attracted roughly 10,000 bets per game during the same period. In terms of dollars bet, although [1] does not directly provide this information, Humphreys et al. [2] obtained dollars bet from an online sportsbook and found that the [1] information on the number of bets are highly correlated with the dollars bet on a game (correlation coefficient of 0.85 ).

Given the thin nature of this betting market and the apparent general lack of interest it generates among most male bettors, it is possible that profitable opportunities may exist in betting the WNBA which would not exist in betting the NBA or other mainstream sports. The nature of the thin market may make it exploitable if sports book managers do not spend the resources to update their information on teams and players. The possibility of market inefficiencies existing in thin betting markets has been explored in horse and dog racing (i.e., Gramm and Owens [3] and Weinbach and Paul [4]). A thin betting market where market efficiency was rejected in team sports was found for the Arena Football League (Borghesi et al. [5]), where betting volume is quite low compared to other North American sports.

If informed bettors do exist within the WNBA betting market, it may be possible to determine their existence through tests for market efficiency and unbiasedness and betting simulations based on simple wagering strategies. If the sports book sets point spreads that are accurate, however, these profitable opportunities may not exist even within the context of this thin market.

To examine this betting market, we obtained WNBA betting data from [1] for the 2007-2012 seasons. The data obtained from [1] not only includes the standard pointspread and game outcome information, but it also includes information on betting percentages. The betting percentages note the percentage of the betting action on favorites and underdogs in this market.

Levitt [6] used data from a betting tournament to illustrate that sportsbooks do not adhere to the balanced book hypothesis. In his study of the NFL, Levitt [6] showed that bettors prefer favorites (in particular road favorites) in that more bets accrue on favorites, and the sportsbook appears to allow unbalanced betting action to maximize profits. Paul and Weinbach [7,8] used data from actual on-line sportsbooks and similarly reject the balanced book hypothesis for the NFL and the NBA. The difference between the NFL and NBA betting markets is that in the NFL, the sportsbook appears to shade the pointspread toward the favorite using their knowledge of the biases of the betting public to earn additional profits. In the NBA, however, the sportsbook does not appear to shade the pointspread, even in the presence of significant imbalances, but appears to price more as a forecast of game outcomes. This difference is likely due to the larger volume of betting which occurs in the NFL compared to the NBA, where sportsbooks may have a greater incentive to undertake the transactions costs to shade the point spread in NFL games compared to NBA games (Paul and Weinbach [8]).

Given the relatively smaller size of the WNBA betting market, does the WNBA market work in the same fashion as the NBA betting market? To examine this question and to explore if there is any evidence of informed betting actions by the wagering public, we explore a few avenues with the gambling data available through [1]. First, we run a simple test for market efficiency based on a regression model of pointspreads and game outcomes. Then, we test if big underdogs and home underdogs win more than implied by efficiency through simple betting simulations. In the NBA, big underdogs and home underdogs were shown to outperform favorites (Paul and Weinbach [8]) as the 
null hypothesis of a fair bet (win percentage is equal to 50\%) could be rejected but the null hypothesis of no profitability (win percentage is equal to $52.4 \%$ - the percentage needed to break even given the bet $\$ 11$ to win $\$ 10$ rule in sports wagering) could not be rejected.

We then use the WNBA betting percentage data to test the null hypothesis of a balanced book (equal betting action on both sides of the wagering proposition). After examining this relationship with respect to the size of the favorite based on the pointspread and a road favorite dummy variable, we explore simple betting simulations based upon wagering with or against the public when a certain threshold of bets accrue on the favorite (i.e., $70 \%$ or more, $60 \%$ or more, etc.). We compare these results to the research performed on the NBA betting market and conclude the paper with some thoughts as to the similarities and differences between these basketball betting markets.

\section{Market Efficiency Tests and Betting Simulations-WNBA}

To begin our analysis, we will test the WNBA betting market under the null hypothesis of market efficiency using standard regression analysis outlined in Zuber et al. [9] and Sauer et al. [10]. Data for the WNBA gambling market was purchased from [1], a website specializing in sports gambling information. The years included in our sample are 2007 through 2012. Games for which no betting action was reported, or in cases where pertinent information was missing, were removed from the sample. Summary statistics for games with home favorites and games with road favorites are shown in the summary statistics below (Table 1).

Table 1. Summary Statistics for Women's National Basketball Association (WNBA) Home and Road Favorites 2007-2012.

\begin{tabular}{cccc}
\hline & Home Favorites & Observations $=\mathbf{9 7 8}$ & \\
\hline & Pointspread & Score Differential & \% Bet on Favorite \\
\hline Mean & 5.98 & 5.25 & 53.50 \\
Median & 5.50 & 6.00 & 54.00 \\
Standard Deviation & 3.26 & 11.58 & 15.29 \\
& Road Favorites & Observations $=\mathbf{3 0 5}$ & \\
Mean & Pointspread & Score Differential & \% Bet on Favorite \\
Median & 4.71 & 3.85 & 68.09 \\
Standard Deviation & 4.00 & 6.00 & 69.00 \\
\hline
\end{tabular}

The basic regression model to test market efficiency in this simple financial betting market takes the form:

$$
\text { Score }=\alpha_{0}+\beta_{1} \text { Line }+\varepsilon_{1}
$$

Score is the scoring differential between the favorite team and the underdog team, Line is the pointspread on the game, and $\varepsilon_{1}$ is the error term with its normal properties. To test for market efficiency, the joint hypothesis is tested that $\alpha_{0}=0$ and $\beta_{1}=1$. Results are presented in Table 2 below.

Using a simple regression-based test, market efficiency in the WNBA betting market is rejected at the $10 \%$ level. The $f$-test that the intercept is equal to zero and the coefficient on the pointspread is equal to one takes a value of 2.82 and rejects market efficiency at the $10 \%$ threshold. Although the 
basic test for market efficiency is rejected, this does not imply that profitable wagering strategies exist. Further tests are necessary to examine if this market offers potential positive betting market returns.

Table 2. Regression Results-Efficiency Test-WNBA. Dependent Variable: Score Differential (Favorite Score-Underdog Score).

\begin{tabular}{cc}
\hline Variable & $\begin{array}{c}\text { Coefficient } \\
\text { (T-Statistic) }\end{array}$ \\
\hline Intercept & -1.01 \\
& $(-1.59)$ \\
Pointspread & $1.05^{* * *}$ \\
F-Test-Intercept $=0$ & $(10.72)$ \\
and Pointspread $=1$ & F-statistic \\
& (Probability Value) \\
\hline$* * *$ : statistical significance of the t-test at the 1\% level.
\end{tabular}

To test for possible profitable betting strategies in the WNBA, we use a simple betting simulation, observing the win-loss record of favorites and underdogs during our sample of the 2007 through 2012 seasons. We break the sample into home and road favorites, due to previous findings of successful wagering strategies based on betting on home underdogs. Research on betting markets have found profitability in wagering on home underdogs in the NFL in studies by Dare and McDonald [11], Golec and Tamarkin [12], and Dare and Holland [13] with similar findings in the NBA in studies such as Paul and Weinbach [8]. It appears across sports using point spreads that there is the tendency for bettors to underestimate the home field advantage of inferior teams (or overestimate the abilitiesof the superior road teams), which could help to explain the favorable results found in wagering on home underdogs.

We choose various thresholds of favorites, denoting big favorites where there is a large enough sample of games to yield potentially meaningful inferences. For home favorites, we present the results for favorites of 10 points or more, 9 points or more, etc. and for the overall sample of home favorites (all). For road favorites, where the implicit home court advantage leads to fewer large road favorites, we choose thresholds of 7 points or more, 6 points or more, etc. and for the overall sample of road favorites (all).

Results related to home favorites are presented in Table 3 and road favorites are presented in Table 4. In each table, favorite wins, underdog wins, pushes (game outcome equals pointspread), win percentage, and log likelihood ratio tests for a fair bet (win percentage equal 0.500) and for no profits (win percentage equal 0.524 ) are presented. The null of a fair bet is a test for unbiasedness of the pointspread. The null of no profits tests if any bias in the pointspread is exploitable compared to transactions costs within the market (overcoming the bookmaker commission).

The log likelihood test statistics have a chi-square distribution with one degree of freedom. Critical Values are 2.70 (for an $\alpha=0.10$ ), 3.84 (for an $\alpha=0.05$ ), and 6.64 (for an $\alpha=0.01$ ). 
Table 3. Betting Simulation Results_-WNBA-Home Favorites.

\begin{tabular}{ccccccc}
\hline $\begin{array}{c}\text { Pointspread } \\
\text { greater than or } \\
\text { equal to: }\end{array}$ & $\begin{array}{c}\text { Favorite } \\
\text { Wins }\end{array}$ & $\begin{array}{c}\text { Underdog } \\
\text { Wins }\end{array}$ & Pushes & $\begin{array}{c}\text { Underdog Win } \\
\text { Percentage }\end{array}$ & $\begin{array}{c}\text { Log Likelihood } \\
\text { Ratio Fair Bet }\end{array}$ & $\begin{array}{c}\text { Log Likelihood } \\
\text { Ratio No Profits }\end{array}$ \\
\hline 10 & 51 & 60 & 2 & $54.05 \%$ & 0.73 & 0.12 \\
9 & 74 & 85 & 2 & $53.46 \%$ & 0.76 & 0.08 \\
8 & 109 & 121 & 4 & $52.61 \%$ & 0.63 & 0.00 \\
7 & 156 & 180 & 5 & $53.57 \%$ & 1.72 & 0.19 \\
6 & 219 & 231 & 7 & $51.33 \%$ & 0.32 & NA \\
5 & 289 & 300 & 8 & $50.93 \%$ & 0.21 & NA \\
ALL & 491 & 472 & 15 & $49.01 \%$ & 0.37 & NA \\
\hline
\end{tabular}

Table 4. Betting Simulation Results—WNBA—Road Favorites.

\begin{tabular}{ccccccc}
\hline $\begin{array}{c}\text { Point spread } \\
\text { greater than } \\
\text { or equal to: }\end{array}$ & $\begin{array}{c}\text { Favorite } \\
\text { Wins }\end{array}$ & $\begin{array}{c}\text { Underdog } \\
\text { Wins }\end{array}$ & Pushes & $\begin{array}{c}\text { Favorite Win } \\
\text { Percentage }\end{array}$ & $\begin{array}{c}\text { Log Likelihood } \\
\text { Ratio Fair Bet }\end{array}$ & $\begin{array}{c}\text { Log Likelihood } \\
\text { Ratio No Profits }\end{array}$ \\
\hline 7 & 42 & 29 & 1 & $59.15 \%$ & 2.39 & 1.32 \\
6 & 55 & 41 & 2 & $57.29 \%$ & 2.05 & 0.93 \\
5 & 70 & 59 & 2 & $54.26 \%$ & 0.94 & 0.18 \\
4 & 82 & 78 & 4 & $51.25 \%$ & 0.10 & NA \\
3 & 99 & 97 & 4 & $50.51 \%$ & 0.02 & NA \\
ALL & 155 & 145 & 5 & $51.67 \%$ & 0.33 & NA \\
\hline
\end{tabular}

The log likelihood test statistics have a chi-square distribution with one degree of freedom. Critical Values are 2.7 (for an $\alpha=0.10$ ), 3.8 (for an $\alpha=0.05$ ), and 6.6 (for an $\alpha=0.01$ ).

With respect to home favorites, underdogs were found to win slightly less than $50 \%$ of the time in the overall sample. These results, however, were not found to be statistically different from $50 \%$ from the log likelihood ratio test. For big home favorites, road underdogs were found to win in excess of $53 \%$ at the various thresholds examined. The null hypothesis of a fair bet (and therefore the null hypothesis of no profitability) could not be rejected at normal significance levels. These results are similar to what was found for the NBA betting market in Paul and Weinbach [8] in that underdogs outperformed favorites, but returns were not great enough to earn statistically significant profits.

Table 3 presented the results for road favorites. In the case of road favorites, the favorite was shown to win more than $50 \%$ of the time overall, with some high win percentages at the highest thresholds observed. In all cases, however, the null hypothesis of a fair bet (and therefore also the null of no profitability) could not be rejected. These results are similar to the NBA (Paul and Weinbach [8]), where statistically significant results were not found in the sample of road favorites.

To test for robustness, we divided the sample in half and did the same tests for the games played early in the sample compared to late in the sample. Large road favorites $(7+, 8+$, and $9+$ point favorites) did perform slightly better in the early part of our sample (2007-2009), rejecting the null hypothesis of a fair bet for these years. In the more recent sample (2010-2012), statistically significant results were not found. Therefore, there is some evidence that the simple strategy of wagering on the 
road underdogs has become less profitable over time. In relation to the sample of road favorites, no statistically significant results were found in either subsample.

Given that road favorites win more than $50 \%$ of the time in the WNBA, it is possible that the home court advantage is slightly overstated (although not statistically significant) in the WBNA betting market. Given that home field advantage incorporates a variety of factors in most sports (unique stadium attributes, being able to sleep at home rather than in a hotel, the intensity of the home crowd); the home field can be a potent factor. In the WNBA, however, home court may not be as pivotal as basketball courts are uniform in nature and small crowds for WNBA games may not affect opponents as much as lively sold-out arenas for sports such as the NBA. In any case, although favorites won more often than underdogs, the returns were not great enough to earn statistically significant results.

\section{Betting Percentage Regression and Betting Simulation Results}

In this section, we examine the determinants of betting percentages for the WNBA in the same manner they were examined for the NBA in Paul and Weinbach [8]. The source of our data, [1], reports the percentage of bets on the favoriteand the underdog. As noted in the introduction, however, Humphreys et al. [2] found that the dollars bet on a game are highly correlated with the number of bets reported by [1]. Therefore, the percentage of dollars bet on the game are highly correlated with the percentage of bets reported in our data set. A very simple regression model is tested, which illustrates the actions of the sportsbook. The model to be estimated is as follows for the sides (pointspread) market:

$(\% \text { Bet on the Favorite })_{\mathrm{i}}=\alpha_{0}+\beta_{1}(\text { Pointspread })_{\mathrm{i}}+\beta_{2}(\text { Dummy for Road Favorite })_{\mathrm{i}}+\varepsilon_{\mathrm{i}}$

The dependent variable is the percentage of dollars bet on the favorite. The independent variables include an intercept, the pointspread on the game (presented as a positive number-greater favorites have larger pointspreads), and a dummy for teams which are road favorites. Road favorites have been shown to be commonly overbet in wagering market studies such as Golec and Tomarkin [12], Gray and Gray [14], and Levitt [6].

A couple of simple propositions can be tested from this regression model. First, if bettors overbet favorites and stronger favorites are bet more heavily than weaker favorites, the coefficient $\beta_{1}$ should be positive and significant. If bettors overbet road favorites, the coefficient on the dummy variable, $\beta_{2}$, should also be positive and significant. Under the balanced book hypothesis of sportsbook behavior, the intercept should be equal to 50 and the other coefficients should be equal to zero. The balanced book hypothesis has been rejected in similar studies for the NFL (Levitt [6]; Paul and Weinbach [7]), NBA (Paul and Weinbach [8]), College Basketball (Paul and Weinbach [15]) and other sports using data from [1] or similar data. Regression results are shown in Table 5 below.

As is the case for the NBA and other sports, the regression results for the WNBA soundly reject the null hypothesis of a balanced book. Although the intercept is found to be slightly under $50 \%$, the percentage bet is found to increase with the magnitude of the favorite (by about three-quarters of a point for each point of the pointspread - significant at the 1\% level) and road favorites are found to be heavily bet in this market, with an additional $15.5 \%$ bet on home favorites in this sample. In short, WNBA bettors, like bettors of other sports, appear to favor the best teams, particularly on the road. 
Table 5. Regression Results-Determinants of Favorite Betting Percentage-WNBA.

Dependent Variable: Percentage Bet on Favorite.

\begin{tabular}{cc}
\hline Variable & $\begin{array}{c}\text { Coefficient } \\
\text { (T-statistic) }\end{array}$ \\
\hline Intercept & $49.07^{* * *}$ \\
& $(55.02)$ \\
Pointspread & $0.74 * * *$ \\
& $(5.81)$ \\
Road Favorite Dummy & $15.56^{* * *}$ \\
& $(16.13)$ \\
\hline$* * *$ statistical significance of the t-test at the 1\% level.
\end{tabular}

To determine if the betting public finds a way to exploit the WNBA betting market, we run simple betting simulations observing results where one particular side of the betting proposition receives a disproportionate share of the betting action. We choose thresholds of $70 \%$ or more, $65 \%$ or more, $60 \%$ or more, and 55\% or more for both home favorites (Table 6) and road favorites (Table 7). As with Tables 3 and 4 in the previous section, favorite wins, underdog wins, pushes, win percentage, and log likelihood ratio tests are presented. If the betting public can successfully pick winners, the more popular side of the proposition should win more than $50 \%$ of the time. In this scenario, the sportsbook would be losing money to bettors as the sportsbook is not balanced.

Table 6. Betting Simulations - Betting with the Public-Home Favorites.

\begin{tabular}{ccccccc}
\hline $\begin{array}{c}\text { Betting Percentage } \\
\text { on Favorite greater } \\
\text { than or equal to: }\end{array}$ & $\begin{array}{c}\text { Favorite } \\
\text { Wins }\end{array}$ & $\begin{array}{c}\text { Underdog } \\
\text { Wins }\end{array}$ & Pushes & $\begin{array}{c}\text { FavoriteWin } \\
\text { Percentage }\end{array}$ & $\begin{array}{c}\text { Log Likelihood } \\
\text { Ratio Fair Bet }\end{array}$ & $\begin{array}{c}\text { Log Likelihood } \\
\text { Ratio No Profits }\end{array}$ \\
\hline 70 & 77 & 67 & 2 & $53.47 \%$ & 0.70 & 0.07 \\
65 & 110 & 106 & 2 & $50.93 \%$ & 0.07 & NA \\
60 & 167 & 160 & 3 & $51.07 \%$ & 0.15 & NA \\
55 & 247 & 226 & 5 & $52.22 \%$ & 0.93 & NA \\
\hline
\end{tabular}

The log likelihood test statistics have a chi-square distribution with one degree of freedom. Critical Values are 2.71 (for an $\alpha=0.10$ ), 3.84 (for an $\alpha=0.05$ ), and 6.63 (for an $\alpha=0.01$ ).

Table 7. Betting Simulations-Betting with the Public—Road Favorites.

\begin{tabular}{ccccccc}
\hline $\begin{array}{c}\text { Betting Percentage } \\
\text { on Favorite greater } \\
\text { than or equal to: }\end{array}$ & $\begin{array}{c}\text { Favorite } \\
\text { Wins }\end{array}$ & $\begin{array}{c}\text { Underdog } \\
\text { Wins }\end{array}$ & Pushes & $\begin{array}{c}\text { Favorite Win } \\
\text { Percentage }\end{array}$ & $\begin{array}{c}\text { Log Likelihood } \\
\text { Ratio Fair Bet }\end{array}$ & $\begin{array}{c}\text { Log Likelihood } \\
\text { Ratio No Profits }\end{array}$ \\
\hline 70 & 74 & 70 & 2 & $51.39 \%$ & 0.11 & NA \\
65 & 101 & 86 & 4 & $54.01 \%$ & 1.20 & 0.20 \\
60 & 126 & 105 & 4 & $54.55 \%$ & 1.91 & 0.44 \\
55 & 135 & 123 & 5 & $52.33 \%$ & 0.56 & NA \\
\hline
\end{tabular}

The log likelihood test statistics have a chi-square distribution with one degree of freedom. Critical Values are 2.71 (for an $\alpha=0.10$ ), 3.84 (for an $\alpha=0.05$ ), and 6.64 (for an $\alpha=0.01$ ). 
For the sample of home favorites (Table 6), when the favorite is significantly overbet compared to the underdog, no statistical significance is found as the null of a fair bet (and no profitability) cannot be rejected. Win percentages are slightly above $50 \%$ in each threshold case studied. For the sample of road favorites (Table 7), win percentages are found to be slightly higher than for home favorites in the thresholds studied for relatively small samples (compared to home favorites). The null of a fair bet and the null of no profitability cannot be rejected in any of the groupings. As in the previous section, we also tested for robustness by dividing the sample in half for the market efficiency tests based upon unbalanced betting. Statistically significant results were not found in either subsample.

Unlike other sports, where either underdogs do slightly better than favorites when the favorites attract a high percentage of the betting action or the results are closer to an even 50/50 split, betting with popular road favorites in the WNBA wins more often than underdogs. If these results were to persist in a larger sample, it they could indicate the existence of some informed WNBA bettors, who are taking advantage of possible mispricing of the home court advantage in WNBA games. In this current sample, however, even though the percentages lean toward some inclination of informed bettors in this thinly-bet market, statistical significance cannot be found.

\section{Conclusions}

The betting market for the WNBA was examined both in terms of game outcomes compared to the pointspread and the preferences of the betting public, using betting percentages on favorites and underdogs. For the most part, the betting market for the WNBA is quite similar to other betting markets, with bettors exhibiting a tendency to wager on the better teams. This tendency to bet on the best teams is consistent with the idea that bettors are often fans, and betting on games may be viewed as a consumption activity, rather than strategic investment. Although market efficiency was rejected using the simple regression model approach, simple betting simulations did not reveal statistically significant results.

Studying the betting percentages on favorites and underdogs revealed a rejection of the balanced book hypothesis. Like other sports, the percentage bet on the favorite increases with each point of the pointspread by a statistically significant margin. In addition, road favorites attract a large (15\%) and statistically significant increase in bets. Road favorites, however, were found to win more often than home underdogs. This is contrary to what is generally observed in other sports, where home underdogs have been shown to win more often than implied by efficiency and, in some cases, earn statistically significant profits (i.e., Levitt [6], Paul and Weinbach [7]). Although favorites outperformed underdogs, statistically significant results were not found. The success of road favorites could reflect a possible overstating of home court advantage in the WNBA by sportsbooks, with smaller crowds at games providing less of an advantage.

With the relatively light volume and lower betting limits (limits of $10 \%-50 \%$ of NBA limits are common in the industry), it may also be the case that sportsbooks choose to invest fewer resources in setting and adjusting the lines in this market, or treat WNBA betting not as a money making proposition, but as a service offered to keep customers actively engaged in between seasons. Mayer [16] indicated that as an illegal bookie, he made little money on baseball betting, but provided it as a service to 
bettors to retain their loyalty and keep customers coming back for the football season. This type of behavior by the sportsbook could attract informed bettors into the market.

To determine if bettors of the WNBA are exploiting the sportsbook for profits, we performed some basic betting simulations based on different threshold levels of percentage bet on the favorite. When favorites, both home and road, attract a disproportionate share of the betting action, the null of a fair bet cannot be rejected with win percentages hovering around $50 \%$ for favorites and underdogs. One finding that was different from the NBA was that popular favorites outperformed their underdog opponents, as road favorites who received a disproportionate share of the betting activity won more than $50 \%$ of the time. As noted above, however, they did not win often enough to earn statistically significant returns.

Overall, the WNBA betting market appears similar to the betting market of the NBA, despite low overall bettor interest. Bettors of the WNBA prefer to bet on the best teams (big favorites), particularly when they are on the road. Even with the thin market and the biased views of bettors, simple betting strategies of wagering against the most popular public wagers did not win often enough to earn statistically significant profits. It appears book makers for the WNBA act in the same fashion as they do in other sports, essentially pricing as a function of expected game outcomes despite clear public preferences for one team over the other. There are either few (if any) informed bettors within the WNBA betting market or their presence (or perceived presence) leads the sportsbook to price as a forecast of game outcomes to discourage their participation. In any case, there does not appear to be easy profits to be made for informed traders within this market.

\section{Author Contributions}

Rodney J. Paul and Andrew P. Weinbach split the research work on this paper. Andrew P. Weinbach found and gathered the data on the WNBA and did background research on the topic. Rodney J. Paul ran the statistical models, and wrote the manuscript, with insight, editing, and help from his co-author.

\section{Conflicts of Interest}

The authors declare no conflict of interest.

\section{References}

1. Sportsinsights. Available online: http://www.sportsinsights.com (accessed on 22 April 2014).

2. Humphreys, B.; Paul, R.; Weinbach, A. Consumption Benefits and Gambling: Evidence from the NCAA Basketball Betting Market. J. Econ. Psychol. 2013, 39, 376-386.

3. Gramm, M.; Owens, D. Determinants of Betting Market Efficiency. Appl. Econ. Lett. 2005, 12, 181-185.

4. Weinbach, A.; Paul, R. The Link between Information and the Favorite-Longshot Bias in Parimutuel Wagering Markets. J. Gambl. Bus. Econ. 2008, 2, 30-44.

5. Borghesi, R.; Paul, R.; Weinbach, A. Market Frictions and Overpriced Favorites: Evidence from Arena Football. Appl. Econ. Lett. 2009, 16, 903-906. 
6. Levitt, S. Why are gambling markets organized so differently from financial markets? Econ. $J$. 2004, 114, 223-246.

7. Paul, R.; Weinbach, A. Does Sportsbook.com Set Pointspreads to Maximize Profits? Tests of the Levitt Model of Sportsbook Behavior. J. Predict. Mark. 2008, 1, 209-218.

8. Paul, R.; Weinbach, A. Price Setting in the NBA Gambling Market: Tests of the Levitt Model of Sportsbook Behavior. Int. J. Sports Financ. 2008, 3, 2-18.

9. Zuber, R.; Gandar, J.; Bowers, B. Beating the spread: Testing the efficiency of the gambling market for National Football League games. J. Polit. Econ. 1985, 93, 800-806.

10. Sauer, R. The Economics of Wagering Markets. J. Econ. Lit. 1998, 36, 2021-2064.

11. Dare, W.; McDonald, S. A Generalized Model for Testing the Home and Favorite Team Advantage in Point Spread Markets. J. Financ. Econ. 1996, 40, 295-318.

12. Golec, J.; Tamarkin, M. The degree of inefficiency in the football betting market: Statistical tests. J. Financ. Econ. 1991, 30, 311-323.

13. Dare, W.; Holland, S. Efficiency in the NFL Betting Market: Modifying and Consolidating Research Methods. Appl. Econ. 2004, 36, 9-15.

14. Gray, P.; Gray, S. Testing market efficiency: Evidence from the NFL sports betting market. J. Financ. 1997, 52, 1725-1737.

15. Paul, R.; Weinbach, A. Investigating Allegations of Pointshaving in NCAA Basketball using Actual Sportsbook Percentages. J. Sports Econ. 2011, 12, 432-447.

16. Mayer, G. Bookie: My Life in Disorganized Crime; J.P. Tarcher, Inc.: Los Angeles, CA, USA, 1974.

(C) 2014 by the authors; licensee MDPI, Basel, Switzerland. This article is an open access article distributed under the terms and conditions of the Creative Commons Attribution license (http://creativecommons.org/licenses/by/3.0/). 